\title{
Improving Teacher Performance using Data Mining
}

\author{
Randa Kh. Hemaid ${ }^{1}$, Alaa M. El-Halees ${ }^{2}$ \\ Faculty of Information Technology, Islamic University of Gaza, Gaza, Palestine ${ }^{1,2}$
}

\begin{abstract}
This study examines the factors associated with the assessment of teacher's performance. To improve the teacher performance, good prediction of training course that will be obtained by teacher in one way to reach the highest level of quality in Teacher performance, but there is no certainty if there are accurately determine Teacher advantage and increase its efficiency through this session. In this case the real data is collected for teachers from the Ministry of Education and Higher Education in Gaza City. It contains data from the academic qualifications for teachers as well as their experience and courses. The data includes three years and questionnaire contains many questions about the course and length of service in the ministry. We propose a model to evaluate their performance through the use of techniques of data mining like association, classification rules (Decision Tree, Rule Induction, K-NN, Naïve Bayesian (Kernel)) to determine ways that can help them to better serve the educational process and hopefully improve their performance and thus reflect it on the performance of teachers in the classroom. In each tasks, we present the extracted knowledge and describe its importance in teacher performance domain.
\end{abstract}

Keywords: Teachers’ Evaluation, Educational Data Mining, Teacher Performance, Classification.

\section{INTRODUCTION}

Data mining refers to extracting knowledge from large amounts of data. It is actually part of the knowledge discovery process. It is the process of extracting knowledge hidden from large volumes of raw data. The knowledge must be new, and must be able to use to discover the hidden patterns and relationships which must be helpful in decision making [1].

Data mining is the analysis of observational data sets to find unsuspected relationships and to summarize the data in novel ways that are both understandable and useful to the data owner. The relationships and summaries derived through a data mining exercise are often referred to as models or patterns [2].

Algorithms and techniques like Classification, Clustering, Regression, Artificial Intelligence, Neural Networks, Association Rules, Decision Trees, Genetic Algorithm, Nearest Neighbor method etc., are used for knowledge discovery from databases [3].

Data mining techniques have been applied in many application domains such as Banking, Fraud detection, Instruction detection and Communication, marketing, medicine, real estate, customer relationship management, engineering, web mining and recently in education which known as Educational Data Mining [4][5].

Most research focused on improving the performance of students and improves the curriculum and what is reflected in the educational process, there are a few researches that have been proposed for teacher performance.

The main objective of this paper is to improve teacher performance through the study of their specialization and expertise and the time of the period in the service of the educational process, evaluate and determine courses for needy teachers under improving their performance. By offering precised directed courses to the teacher according to his need and build on what he has from previous knowledge. So the training adds new information and knowledge to the experience and improves his Copyright to IJARCCE performance in the classroom and in the delivery of scientific material for students, and how to manage time and deal with the modern means.

The Ministry of Education suffers in directing teachers training courses. They have to be classified according to their need for the session; teachers classified in the courses training inaccurately so they are not taking the previous experience of the teacher in this area, therefore the evaluation set to some extent is inaccurate.

The main goal of this research is to develop a model based on data mining that evaluates the performance of teachers, apply our approach on real data sets.

This paper investigates the educational domain of data mining using a case study from the teacher data collected from the Ministry of Education Gaza and Information on training courses include three years in period [2010-2013]. It showed how could we preprocess the data, how to apply data mining methods on the data, and finally how can we benefited from the discovered knowledge. There are many kinds of knowledge can be discovered from the data. In this work we investigated the most common ones which are association rules, classification. The Rapid Miner software is used for applying the methods on the teacher's data set.

This paper takes into consideration the ethical and privacy issues. Official approval from the Ministry of Education Gaza was obtained for access to the related data for the sole use of analysis and knowledge discovery. All personal data are extracted from the database before applying the data mining methods.

The rest of this paper is organized as follows: Section 2 presents related works in educational data mining. Section 3 describes the data set and the preparation and processing methods performed. Section 4 reports our experiments about applying data mining techniques on the educational data. Finally we conclude this paper with a summary and an outlook for future work in Section 5. 


\section{RELATED WORKS}

There are many works in this area. On improving the performance of students and improve the curriculum and what is reflected in the educational process and on improving teacher performance.

Baradwaj and Pal [3] used classification task to evaluate student's performance. The decision tree method is used also for predicting student performance. By this task they extract knowledge that describes students' performance in final semester examination. It helps earlier in identifying the dropouts and students who need special attention to reduce failure ration and allow the teacher to provide appropriate advising or to provide counseling and taking appropriate action for the next semester examination.

Yadav and Pal [5] used C4.5, ID3 and CART decision tree algorithms on engineering student's data to predict their performance in the final exam. Prediction models that include all personal, social, psychological and other environmental variables are necessary for the effective prediction of the performance of the students. C4.5 technique has highest accuracy of $67.7778 \%$ compared to other methods ID3 and CART algorithms. From the classifiers accuracy the true positive rate of the model for the FAIL class is 0.786 for ID3 and C4.5 decision trees. They can produce short but accurate prediction list for the student by applying the predictive models to the records of incoming new students.

Ola and Pallaniappan [6] used directed modeling an intelligent technique for evaluation of instructors' performance in higher institutions of learning, and proposed an optimal algorithm and designed a system framework which is suitable for predicting instructors' performance. The proposed system, if fully implemented, will aid school administrators in decision making, provide basis for instructors' performance improvement that will optimize students' academic outcomes and improve standard of education. Consequently, this will contribute to successful achievement of the goals.

Ahmadi and abadi [7] analyzed the performance of final Teacher Evaluation of a semester of a college and presented the result which is achieved using WEKA tool. Data used in this study were 104 records on teacher's behaviors in classroom with data mining algorithms such Association Rule and decision trees (j48). At teacher's evaluation, evaluation's score of students is very important factor.

Correctness of rules depends on a variety of data sets and statistical instances which can vary. But data mining tools such as WEKA can conclude variety results that help education managers in universities. These results will be used by managers in decision-making to submit new teachers and continue with elected old teachers.

Ajay and Saurabh [8] discussed the teachers' performance evaluation using data mining techniques at university teachers. The techniques used are Naive Bayes, ID3, CART and LAD tree.

Bayes classifier has more accuracy with $80.35 \%$ followed by LAD tree with a percentage of $75.00 \%$ and subsequently CART with $65.17 \%$. Content Arrangement impacts output the most effect. The speed of delivery attribute did not show any clear effect while the overall completion of course and regularity attribute has shown some effect in some of the experiments for predicting the performance.

Mardikyan and Badur [9] this study was conducted to understand the key factors affecting the teaching performance of the instructors, identifying the factors associated with the teaching performance, during the period 2004-2009.

They used two different data mining techniques; stepwise regression and decision trees.

They show that a small average relationship exists between learning and the evaluations but not applicable to all teachers. The employment status of the instructor that is not included in the questionnaire is found to be significant. The most important factor to explain the instructors' teaching performance is the instructor attitudes that are primarily measured by the evaluation process. The attendance of the student is another important factor that influences positively the performance of the instructor. Hence, the instructors that attract more students to the classes are evaluated more successfully.

\section{III.THE TEACHER DATA SET AND PREPROCESSING}

The data set used in this paper contains teacher's information collected from the Ministry of Education Gaza and Information on training courses include three years in period from 2010 to 2013. Teacher data set consists of 813 records and 46 attribute after combine the training, administrative and questionnaire information for that has winner training. Table 1 presents the attributes and their description that exists in the data set as taken from the source database.

TABLE I

THE TEACHERS DATA SET DESCRIPTION

\begin{tabular}{|c|c|c|}
\hline Attribute & Description & Selected \\
\hline Teacher_name & The name of teacher & \\
\hline Teacher ID & The ID number of teacher & \\
\hline Classification & $\begin{array}{l}\text { The Classification of teacher; } \\
\text { Workbook and installed, } \\
\text { workbook is not installed or under } \\
\text { appointment }\end{array}$ & $\sqrt{ }$ \\
\hline Qualification & $\begin{array}{l}\text { The Qualification of teacher; } \\
\text { Institute, diploma, college medium, } \\
\text { BA, MA, Ph.D. }\end{array}$ & $\sqrt{ }$ \\
\hline Specific & $\begin{array}{l}\text { The Specific of teacher; Classroom } \\
\text { teacher, Arabic language, Islamic } \\
\text { studies, and so on }\end{array}$ & \\
\hline Course1 & $\begin{array}{l}\text { The Scientific material taught by } \\
\text { the teacher }\end{array}$ & $\sqrt{ }$ \\
\hline Class1 & The Class taught by a teacher & $\sqrt{ }$ \\
\hline Course2 & $\begin{array}{l}\text { The Scientific material taught by } \\
\text { the teacher to complement redress } \\
\text { of classes }\end{array}$ & $\sqrt{ }$ \\
\hline Class2 & The Class taught by a teacher & $\sqrt{ }$ \\
\hline Date_Of_Work & $\begin{array}{l}\text { Date that has been set by the } \\
\text { teacher; } \\
\text { IF Date_Of_Work }<=1 \text { year He's " } \\
\text { New teacher" } \\
\text { IF Date_Of_Work }<=10 \&>1 \\
\text { years he's "Teacher " } \\
\text { IF Date_Of_Work }<=15 \&>10\end{array}$ & $\sqrt{ }$ \\
\hline
\end{tabular}


International Journal of Advanced Research in Computer and Communication Engineering Vol. 4, Issue 2, February 2015

\begin{tabular}{|c|c|c|}
\hline & $\begin{array}{l}\text { years he's " First teacher " } \\
\text { IF Date_Of_Work > } 15 \text { years he's " } \\
\text { Expert teacher" }\end{array}$ & \\
\hline Workplace & The School in which teacher works & \\
\hline $\begin{array}{l}\text { Upper_Workpl } \\
\text { ace }\end{array}$ & $\begin{array}{l}\text { Directorate-affiliated school, which } \\
\text { works out teacher; Directorate of } \\
\text { Education, west of Gaza, } \\
\text { Directorate of Education, east of } \\
\text { Gaza, And the Directorate of } \\
\text { Education in northern Gaza. }\end{array}$ & $\sqrt{ }$ \\
\hline $\begin{array}{l}\text { Number of } \\
\text { days of training } \\
\text { course } 1\end{array}$ & $\begin{array}{l}\text { The number of days where he got } \\
\text { his first training session in the last } 3 \\
\text { years }\end{array}$ & \\
\hline $\begin{array}{ll}\text { Number } & \text { of } \\
\text { hours } & \text { of } \\
\text { training } & \\
\text { course1 } & \\
\end{array}$ & $\begin{array}{l}\text { The number of hours where he got } \\
\text { his first training session in the last } 3 \\
\text { years }\end{array}$ & $\sqrt{ }$ \\
\hline Course Name1 & $\begin{array}{l}\text { The name the first training session } \\
\text { in the last } 3 \text { years }\end{array}$ & $\sqrt{ }$ \\
\hline $\begin{array}{l}\text { Year training } \\
\text { course1 }\end{array}$ & $\begin{array}{l}\text { The Year training course; } \\
2010,2011,2012\end{array}$ & $\sqrt{ }$ \\
\hline $\begin{array}{ll}\begin{array}{l}\text { Number } \\
\text { hours }\end{array} & \text { of } \\
\text { training } & \text { of } \\
\text { course2 } & \\
\end{array}$ & $\begin{array}{l}\text { The number of hours where he got } \\
\text { his second training session in the } \\
\text { last } 3 \text { years }\end{array}$ & $\sqrt{ }$ \\
\hline Course Name2 & $\begin{array}{l}\text { The name the second training } \\
\text { session in the last } 3 \text { years }\end{array}$ & $\sqrt{ }$ \\
\hline $\begin{array}{l}\text { Year training } \\
\text { course2 }\end{array}$ & $\begin{array}{l}\text { The Year training course; } \\
2010,2011,2012\end{array}$ & $\sqrt{ }$ \\
\hline Q1 & $\begin{array}{l}\text { Provide trainees with modern ways } \\
\text { of teaching. }\end{array}$ & $\sqrt{ }$ \\
\hline $\mathrm{Q} 2$ & $\begin{array}{l}\text { Develop the spirit of teamwork } \\
\text { among the trainees through training } \\
\text { activities. }\end{array}$ & $\sqrt{ }$ \\
\hline Q3 & $\begin{array}{l}\text { Encourage trainees to give their } \\
\text { opinions freely and accept the } \\
\text { opinions of others at the same time. }\end{array}$ & $\sqrt{ }$ \\
\hline Q4 & $\begin{array}{l}\text { Let the trainee's acquire teaching } \\
\text { skills such as classroom } \\
\text { management, time management, the } \\
\text { use of a number of modern } \\
\text { educational technologies. }\end{array}$ & $\sqrt{ }$ \\
\hline Q5 & $\begin{array}{l}\text { Let the trainee's acquire a number } \\
\text { of academic skills in terms of the } \\
\text { expansion of the scientific article. }\end{array}$ & $\sqrt{ }$ \\
\hline Q6 & $\begin{array}{l}\text { Pave the session to move the } \\
\text { teacher to teach descriptive higher } \\
\text { stages. }\end{array}$ & $\sqrt{ }$ \\
\hline Q7 & $\begin{array}{l}\text { The course aims to prepare trainers } \\
\text { from the teachers. }\end{array}$ & $\sqrt{ }$ \\
\hline Q8 & $\begin{array}{l}\text { The session achieved its assigned } \\
\text { objectives. }\end{array}$ & $\sqrt{ }$ \\
\hline Q9 & $\begin{array}{l}\text { The practical preparation of the } \\
\text { trainers is appropriate for each } \\
\text { session. }\end{array}$ & $\sqrt{ }$ \\
\hline Q10 & $\begin{array}{l}\text { Coaches make the necessary } \\
\text { assistance to the trainees. }\end{array}$ & $\sqrt{ }$ \\
\hline Q11 & $\begin{array}{l}\text { Allowing trainees to participate } \\
\text { actively. }\end{array}$ & $\sqrt{ }$ \\
\hline Q12 & $\begin{array}{l}\text { Encourage trainees to accomplish } \\
\text { the assigned duties. }\end{array}$ & $\sqrt{ }$ \\
\hline Q13 & $\begin{array}{l}\text { Trainers use modern teaching } \\
\text { methods :( a smart whiteboard, } \\
\text { PowerPoint, e-learning,.....) }\end{array}$ & $\sqrt{ }$ \\
\hline Q14 & $\begin{array}{l}\text { Field follow-up to see how to take } \\
\text { advantage and the extent of the } \\
\text { application in the field. }\end{array}$ & $\sqrt{ }$ \\
\hline Q15 & $\begin{array}{l}\text { Coach treated well and without } \\
\text { moral Come. }\end{array}$ & $\sqrt{ }$ \\
\hline Q16 & $\begin{array}{l}\text { Encourage discussion and exchange } \\
\text { of views. }\end{array}$ & $\sqrt{ }$ \\
\hline Q17 & $\begin{array}{l}\text { Coach takes into account the levels } \\
\text { of all trainees. }\end{array}$ & $\sqrt{ }$ \\
\hline
\end{tabular}

\begin{tabular}{|c|c|c|}
\hline Q18 & $\begin{array}{l}\text { Trainer has efficiency which is } \\
\text { suitable for the level of the session. }\end{array}$ & $\sqrt{ }$ \\
\hline Q19 & $\begin{array}{l}\text { The actual need of the trainees for } \\
\text { this training. }\end{array}$ & $\sqrt{ }$ \\
\hline Q20 & $\begin{array}{l}\text { Add new experiences to the trainees } \\
\text { through this training. }\end{array}$ & $\sqrt{ }$ \\
\hline Q21 & $\begin{array}{l}\text { Give the trainees possibility of the } \\
\text { use of the information gained from } \\
\text { this training in their teaching in the } \\
\text { future. }\end{array}$ & $\sqrt{ }$ \\
\hline Q22 & $\begin{array}{l}\text { Convenient ways of training } \\
\text { materials for scientific } \\
\text { studied by coaches. }\end{array}$ & $\sqrt{ }$ \\
\hline Q23 & $\begin{array}{l}\text { The clarity of the objectives of the } \\
\text { session for the trainees. }\end{array}$ & $\sqrt{ }$ \\
\hline Q24 & $\begin{array}{l}\text { Trainers feel with comfort and } \\
\text { satisfaction of trainees for the } \\
\text { session. }\end{array}$ & $\sqrt{ }$ \\
\hline Q25 & $\begin{array}{l}\text { Begins the session with knowledge } \\
\text { of (past experiences) of trainees. }\end{array}$ & $\sqrt{ }$ \\
\hline Q26 & $\begin{array}{l}\text { Classification of trainees in courses } \\
\text { according to their levels. }\end{array}$ & $\sqrt{ }$ \\
\hline Q27 & $\begin{array}{l}\text { The course length is sufficient for } \\
\text { the benefit of the trainee as } \\
\text { required. }\end{array}$ & $\sqrt{ }$ \\
\hline Q28 & $\begin{array}{l}\text { The trainees have implemented the } \\
\text { experience they have gained in their } \\
\text { classrooms. }\end{array}$ & $\sqrt{ }$ \\
\hline Q29 & $\begin{array}{l}\text { The session has improved the } \\
\text { professional competence. }\end{array}$ & $\sqrt{ }$ \\
\hline
\end{tabular}

As part of the data preparation and preprocessing of the data set and to get better input data for data mining techniques, we did some preprocessing for the collected data before loading the data set to the data mining software, irrelevant attributes should be removed. The attributes marked as selected as seen in Table 1 are processed via the rapid miner software to apply the data mining methods on them. The attributes such as the Teacher_Name or Teacher_ID, etc. are not selected to be part of the mining process; this is because they do not provide any knowledge for the data set processing and they present personal information of the teacher.

- The following steps are performed as part of the preparation and preprocessing of the data set: The Date_Of_Work attribute in the data set contains a large number of values. So we grouped it into Four categorical segments; New teacher, Teacher, First teacher and Expert teacher as follows: IF Date_Of_Work $<=1$ year He's "New teacher" IF Date_Of_Work $<=10 \&>1$ years he's "Teacher " IF Date_Of_Work $<=15 \&>10$ years he's "First teacher " IF Date_Of_Work >15 years he's "Expert teacher"

- $\quad$ No. _hour attribute in the data set contains a large number of values. So we grouped it into three categorical segments; long training, medium training and short training.

- The training_year attribute in the data set contains the detailed date, we dispensed the day and month and using the year only.

- We made a questionnaire to get some information about the courses received by teachers in the training centers of the directorates so that it contains the questionnaire on three main pivots (Goals courses, 
trainees, trainers) and includes 29 questions which are answered through (OK, to some extent, I do not agree)

- $\quad$ The school name attribute in the data set contains a large number of values. So for efficient processing, we have dispensed this attribute, using Upper_workplace ( Directorate).

\section{IV.APPLICATION OF DATA MINING TECHNIQUES TEACHERS DATA SET: RESULT AND DISCUSSION}

Figure 1 depicts the work methodology used in this search, which is based on the framework proposed. The methodology starts from the data collection, then preprocessing which are discussed in the Teacher Data Set and Preprocessing, and then we come to the data mining methods which are association and classification followed by the evaluation of results, finally the knowledge representation process.

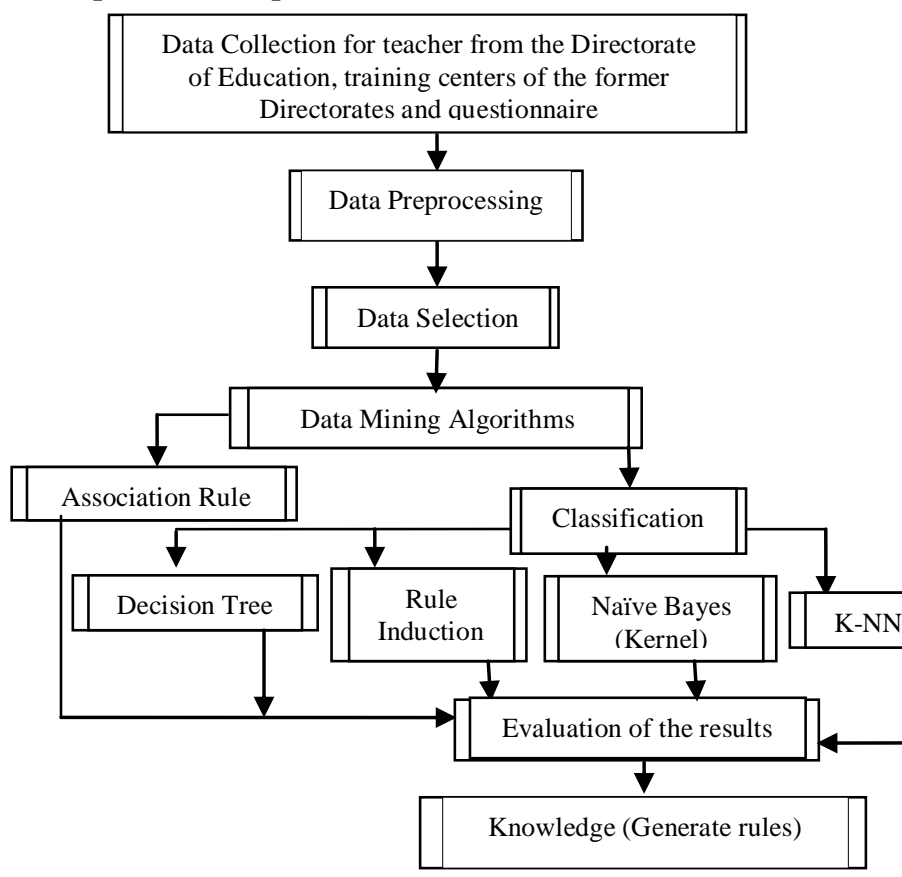

Figure 1 presents methodology of our proposed approach.

\section{A. Association Rule}

We used this experiment as a baseline to know the question which has related to question 29" The session has improved the professional competence ".

In our data set an example of item is: Question 29 "The session has improved the professional competence "=1"agree". Because, we are looking for items that characterize the Improved session of professional competence of Teacher, consequent has one item which is Improved session of professional competence $=\mathrm{x}$ where $\mathrm{x}$ is one value of the Answer the questionnaire such as agree, OK somewhat, not agree. As part of association method, FP-Growth algorithm is applied to the data set.

Figure 2 depicts a sample of association rules discovered from data for Teacher with question 29 " The session has improved the professional competence " agree, with their support, confidence, and lift.

\begin{tabular}{|c|c|c|c|c|c|c|c|c|}
\hline Premioses & Condision & sumon & Coritenes & LPPQDe & Gin & ps & lit & canitoly \\
\hline 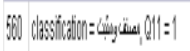 & QW: $=1$ & 040 & 000 & 0000 & .1790 & Q1:3 & 1.892 & 1642 \\
\hline 6MI All:1 & $M=1$ & 0.44 & UQW & 0.081 & .0786 & 01:28 & 1.48 & 10.000 \\
\hline 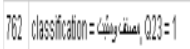 & 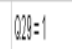 & 040 & QNOP & 1089 & .0786 & 0.38 & 140 & 1.00 \\
\hline $771003: 1$ & $M: 1$ & 046 & lif1 & 009 & $.177 \%$ & 0.14 & 1.49 & 1888 \\
\hline 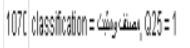 & QW: $=1$ & O.44 & 0.801 & 0916 & .1087 & 0.165 & $100 \%$ & 260 \\
\hline $10802015=1$ & $M P=1$ & 040 & $0.0 \%$ & 096 & .1898 & 0150 & 1.007 & 2224 \\
\hline 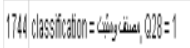 & $M O=1$ & 0407 & 1048 & 0.30 & .1560 & 0.179 & 1.780 & 340 \\
\hline $1756008=1$ & $Q D=1$ & 044 & LQP & 0.50 & .550. & 0182. & 1784 & 36.4 \\
\hline
\end{tabular}

These rules are sorted by lift metric. The lift value is the ratio of the confidence of the rule and the expected confidence of the rule and it is used in measuring the interest of the rule [10].

The lift value of greater than 1 indicates a positive correlation between antecedent and consequent and the occurrence of one implies the occurrence of the other.

For example the first rule with lift is 1.432 means there is a high positive correlation between the Q29 "The session has improved the professional competence" and the Q11" Allowing trainees to participate actively ". With the lift value, we can measure the importance of a rule.

The Third rule with lift is 1.490 means there is a high positive correlation between the Q29 "The session has improved the professional competence" and the Q23" The clarity of the objectives of the session for the trainees".

The last rule, with the highest lift which means highest correlation is the most important, and so on.

To interpret the rules in the association rules model, the first rule means that the teacher Allows trainees to participate actively, $40.7 \%$ (support), $68 \%$ probability (confidence) that teachers have gotten Improved session of professional competence, the Third rule means that of The clarity of the objectives of the session for the trainees, $42.0 \%$ (support), $70.8 \%$ probability (confidence) that teachers have gotten Improved session of professional competence, and so on.

\section{B. Decision Tree}

Decision tree learning is a common method used in data mining. It is an efficient method for producing classifiers from data. It is a tree-structured plan of a set of attributes to test in order to predict the output.

It is a type of tree-diagram used in determining the optimum course of action, in situations having several possible alternatives with uncertain outcomes [11] 


\section{Tree}

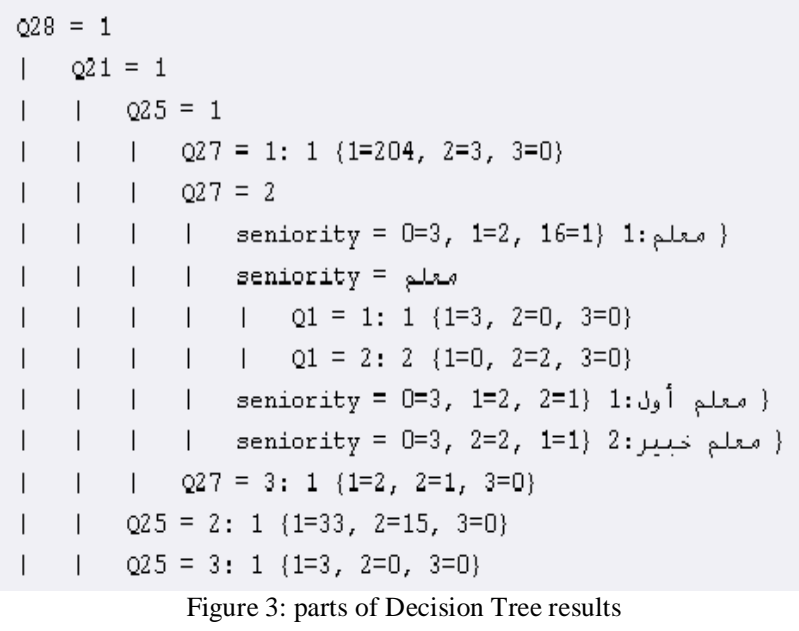

Figure 3 depicts the part of rules that resulted from applying the Decision Tree classification algorithm on the Q29 "The session has improved the professional competence." of the teacher as a target class. As it is seen from the figure to interpret the rules in the decision tree, the first rule says that, if the trainees have implemented experience they have gained in their classrooms and give the trainees possibility of the use of the information gained from this training in their teaching in the future and begins the session with knowledge of (past experiences) of the trainees and the course length is sufficient for the benefit of the trainee as required, the session has improved the professional competence can be predicted as ok by a high proportion.

Another rule says that, if the trainees have implemented experience they have gained in their classrooms and give the trainees possibility of the use of the information gained from this training in their teaching in the future and begins the session with knowledge of (past experiences) of the trainees ok to some extent, the session has improved the professional competence can be predicted as ok by a medium proportion.

The findings show that relationship exists between the session has improved the professional competence, the trainees have implemented the experience they have gained in their classrooms, give the trainees possibility of the use of the information gained from this training in their teaching in the future, the session begins with knowledge of (past experiences) of the trainees, the course length is sufficient for the benefit of the trainee as required, convenient ways of training materials for scientific subjects studied by coaches, trainer feel with comfort and satisfaction of trainees for the session, encourage trainees to accomplish the assigned duties, the clarity of the objectives of the session for the trainees, field of followup to see how to take advantage and the extent of the application in the field and The course aims to prepare trainers from the teachers.

Copyright to IJARCCE

\section{Rule Induction}

Figure 4 depicts the rules that resulted from applying the Rule Induction classification algorithm on the Q29 "The session has improved the professional competence." of the Teacher as a target class. As it is seen from the figure, the attributes that category of the target class are the Q28" The trainees have implemented the experience they have gained in their classrooms", the Q25" Begins the session with knowledge of (past experiences) of the trainees ", the Q 6" Pave the session to move the teacher to teach descriptive higher stages ", the Q16" Encourage discussion and exchange of views", the Q21" Give the trainees possibility of the use of the information gained from this training in their teaching in the future", and the Q24" trainer feel with comfort and satisfaction of trainees for the session", the model presented in figure 5.3 has an accuracy of $76.23 \%$ which has acceptable accuracy and we suggest using Rule Induction algorithm for predicting the Q29 " The session has improved the professional competence " of the Teacher.

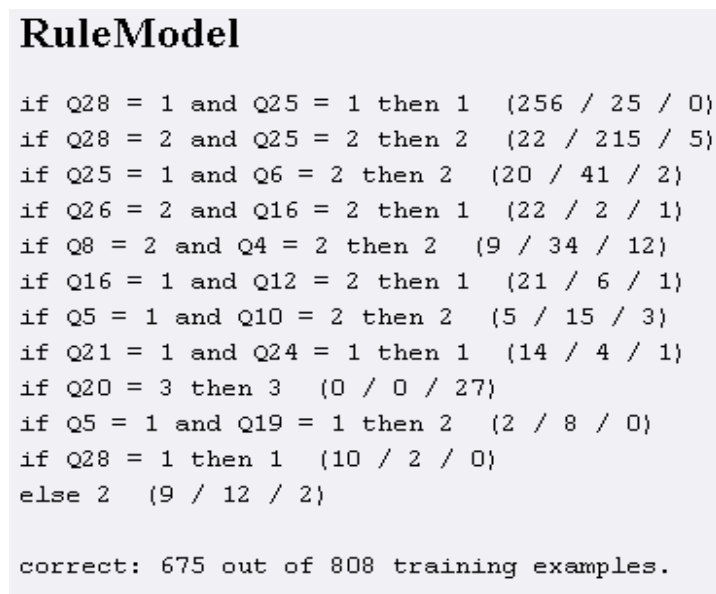

Figure 4: Rule Induction results

The most relevant variable to the session has improved the professional competence, the trainees have implemented the experience they have gained in their classrooms is positively related with this variable. The second related variable is Begins the session with knowledge of (past experiences) of the trainees then Give the trainees possibility of the use of the information gained from this training in their teaching in the future and the trainer feels with comfort and satisfaction of trainees for the session.

The result that we obtained by using decision tree similar with the result obtain by rule induction.

D. Nä̈ve Bayesian (Kernel)

Naïve Bayesian classifier is a technique for estimating probabilities of individual variable values, given a class, from training data and then allow the use of these probabilities to classify new entities [11].

Figure 5 presents the Distribution model for label attribute Q29" The session has improved the professional competence " that resulted from applying the Naïve Bayesian Kernel classifier, the model has an accuracy of $77.46 \%$ which is acceptable accuracy and we suggest using Naïve Bayesian method for predicting the Improved session of professional competence for teacher. 


\begin{tabular}{|c|c|c|c|c|}
\hline & nol & toe? & tove3 & dassperision \\
\hline pedil & 102 & 17 & 1 & 65007 \\
\hline ped? & 12 & 76 & 8 & $73000 \%$ \\
\hline ped 3 & 0 & 9 & 11 & $3500 \%$ \\
\hline lasseredal & $8228 \%$ & 74518 & 01.118 & \\
\hline
\end{tabular}

Figure 5: Naïve Bayesian (Kernel) results

\section{E. $K-N N$}

$\mathrm{K}$ nearest neighbors is a simple algorithm that stores all available cases and classifies new cases based on a similarity measure [12].

Figure 6 presents the Distribution model for label attribute Q29" The session has improved the professional competence." that resulted from applying the K-NN classifier, when $\mathrm{K}=6$ the model has an accuracy of $79.92 \%$ which is acceptable accuracy.

\begin{tabular}{|c|c|c|c|c|}
\hline \\
\hline \multicolumn{5}{|c|}{ эсcuracy, $79.92 \%$} \\
\hline pred. 1 & 111 & 27 & 1 & 7986 \\
\hline pred. 2 & 13 & 74 & 7 & 7872 \\
\hline pred 3 & 0 & 1 & 10 & 9091 \\
\hline class recall & $69.52 \%$ & $72.55 \%$ & $55.56 \%$ & \\
\hline
\end{tabular}

Figure 5: K-NN results

\section{CONClusion}

This study examines the factors associated with the assessment of teaching performance of teachers, Good prediction of training course that will be teacher obtain it's way to reach the highest level of quality in her/his performance. we used data which collected from teachers administrative information collected from the Directorate of Education, west of Gaza, Directorate of Education, east of Gaza, And the Directorate of Education in northern Gaza, Information on training courses by winning teachers in the past three years from 2010 to 2013 Were obtained from the training centers of the former Directorates each center individually training Center at Almagdh Waseela "west of Gaza", training center in eastern Gaza, training center in northern Gaza, Information on training courses and trainees and trainers through the identification of several topics discussed by using questionnaire teacher answering it's. We applied data mining techniques to discover knowledge like association, classification rules (Decision Tree, Rule Induction, K-NN and Naïve Bayesian (Kernel)) to determine ways that can help them to better serve the educational process. The important result by implementation association rule that improve $s$ session of professional competence by achieve: Allowing trainees to participate actively, the clarity of the objectives of the session for the trainees, Begins session with knowledge (past experiences) of the trainees, implemented trainees experience they have gained in their classrooms. By implementation Decision Tree the important rules that related session of professional competence are: Implemented trainees experience they have gained in their classrooms, course length is sufficient for the benefit of the trainee as required, Begins session with knowledge (past experiences) of the trainees. Rule induction the session of professional competence with accuracy of $76.23 \%$ if: Implemented trainee's experience they have gained in their classrooms, Begins session with knowledge (past experiences) of the trainees, Pave the session to move the teacher to teach descriptive higher stages and Encourage discussion and exchange of views. By applying the K-NN classifier, the model has an accuracy of $79.92 \%$ which is acceptable accuracy; But By applying the Naïve Bayesian Kernel classifier, the model has an accuracy of $77.46 \%$ which is acceptable accuracy.

\section{ACKNOWLEDGMENT}

I would like to thank greatly my God for helping me in doing this work.

In addition, I would like to thank those people who have supported me, among those sincere people my beloved mother and my faithful husband. I will never forget to thank my children who were very patient.

I can't deny that I have gained a lot of help and strength from the prayers of my father (may Allah bless his spirit). My sincere thanks are to my supervisor. Thanks a lot to him for his deep encouragement, guide and support from the beginning to the end of this research to get it complete and perfect.

I have to thank employees in the ministry of education for the facilities they offered in obtaining the information about the study sample.

\section{REFERENCES}

[1] DATA MINING TUTORIAL Simply Easy Learning by tutorialspoint.com

[2] Hand, D., Mannila, H., and Smyth, P. Principles of Data Mining, The MIT Press, 2001 (546 pages), A comprehensive, highly technical look at the math and science behind extracting useful information from large databases.

[3] Baradwaj, B. and Pal, S. Mining Educational Data to Analyze Students' Performance, International Journal of Advanced Computer Science and Applications, Vol. 2, No. 6, 2011.

[4] Naeimeh, D. and Mohammad, B., and Somnuk, P. Application of Enhanced Analysis Model for Data Mining Processes in Higher Educational System, In Proceedings of the ITHET 6th Annual International Conference, IEEE, 2005.

[5] Yadav, S. and Pal, S. Data Mining: A Prediction for Performance Improvement of Engineering Students using Classification, World of Computer Science and Information Technology Journal (WCSIT) ISSN: 2221-0741 Vol. 2, No. 2, 51-56, 2012.

[6] Ola, A., and Pallaniappan,S., A data mining model for evaluation of instructors'performance in higher institutions of learning using machine learning algorithms, International Journal of Conceptions on Computing and Information Technology Vol. 1, sue 2, Dec' 2013; ISSN: 2345 - 9808

[7] Ahmadi,F.,and Abadi, S. Data Mining in Teacher Evaluation System using WEKA, International Journal of Computer Applications (0975 - 8887)Volume 63 - No.10, February 2013.

[8] Pal,A., and Pal, s., Evaluation of Teacher's Performance: A Data Mining Approach, International Journal of Computer Science and Mobile Computing, IJCSMC, Vol. 2, Issue. 12, December 2013, pg. 359 - 369

[9] Mardikyan, S. and Badur, B. Analyzing Teaching Performance of Instructors Using Data Mining Techniques, Informatics in Education, Vol. 10, No. 2, 245-257, 2011, Vilnius University.

[10] Sheikh, L., Tanveer, B. and Hamdani, S. Interesting Measures for Mining Association Rules, IEEE-INMIC - Conference Proceedings, 2004.

[11] Han, J. and Kamber, M. Data Mining: Concepts and Techniques, 2nd edition. The Morgan Kaufmann Series in Data Management Systems, Jim Gray, Series Editor, 2006.

[12] http://www.saedsayad.com/k_nearest_neighbors.htm 